\title{
HEINSTROM, Jannica. From Fear to Flow: Personality and information interaction
}

\section{London: Chandos Publishing 2010. 240 pages. ISBN-13: $9781843345138 . £ 45.00$}

The book is survey of how personality dimensions affect people's interactions with information search and use. Presenting a blend of psychology and personality theory and information research, concepts are described clearly with minimal technical language Research claims are robustly referenced. Heinstrom's arguments will be accessible to those unfamiliar with the psychological literature.

Whilst the theories are of interest in themselves, the ideas presented would be of use to all those providing frontline services. For example, the concept of library anxiety is explored ("a well documented and common phenomenon relating to the often puzzling and intimidating structure of information environments." (p96) How might we take this into consideration to arrange our services to meet users in their comfort zone? For those providing library-based training and instruction, this book will inspire thinking on how we can engage all kinds of users.

Five robust and key personality traits are presented and described, and their influence on information acquisition:

- openness to experience

- conscientiousness

- extroversion

- agreeableness

- negative affectivity

Whilst acknowledging that personality is not completely deterministic, and that context is also important (looking up train times in a hurry is a very different kind of information need than beginning research for a masters' thesis), we are invited to consider how the different dimensions of the traits may operate. Cartoon caricatures of the extremes help crystallize this operationalisation, yet we are cautioned not to oversimplify. Other personality dimensions are also considered in lesser detail.

Research is presented on a number of areas of information seeking undergraduates, postgraduate students and jobseekers as well as health-related search. The various ways in which patients search for and deal with information about their illness, based on personality, may have interesting implications for those involved with the provision of the information. This is true for the physical illnesses such as cancer as well as thinking about the implications for mental health work. Affect (mood) as well as personality plays a part - happy people feel more competent as web surfers, so a good mood will have an influence on outcomes of search sessions.

The concepts and frameworks described will be food for thought for many practitioners, and we are also counseled to understand our own strengths and 
weaknesses in our information search. It is an interesting and accessible introduction to the subject.

\section{Sara Batts}

Senior Research Librarian, Reed Smith LLP/ Research student, Loughborough University

s.batts@lboro.ac.uk 